\title{
Biodegradation of Natural Oils in Seawater
}

\author{
M. M. AL-DARBI \\ N. O. SAEED \\ M. R. ISLAM \\ Faculty of Engineering \\ Dalhousie University \\ Halifax, NS, Canada
}

\section{K. LEE}

Bedford Institute of Oceanography

Dartmouth, NS, Canada

\begin{abstract}
Spills of non-petroleum hydrocarbons including vegetable oils and fish oils are of environmental concern because of their potential to cause serious effects on marine life and coastal environments. Biodegradation by indigenous microorganisms is an important and potentially ubiquitous process affecting both the chemical composition and physical properties of contaminant oils. Data on the environmental persistence of non-petroleum oils is now required for risk assessments and decision making by spill responders. This article investigates the biodegradability of various vegetable and fish oils under the influence of natural bacteria in seawater.

The influence of nutrients and microbial environment on changes in bacterial numbers and the extent and rate of degradation for various test oils (olive, mustard, canola and cod liver oils) were studied over time. Time-series visual and microscopic observations were made to characterize physical changes in the residual oils, formation of floating and precipitate particles, oil droplets and dispersion.

The biodegradation process was significantly influenced by environmental conditions, with a higher rate and extent of biodegradation observed in seawater amended with nutrients and wastewater that contained elevated numbers of bacteria and nutrients. It was observed that different oils respond in different rates and extents to biodegradation depending on their stability, viscosity and compositions. All results clearly revealed a significant response of the oil-contaminated samples to both the seawater and wastewater environments. Observations on changes in the physical properties of the residual oil may be important in the context of oil spill response strategies. For example, simple physical recovery methods may be used to recover polymeric lumps at the sea surface.
\end{abstract}

Keywords auto-oxidation, biodegradation, marine bacteria, natural oils, seawater

Received January 15, 2000; accepted August 31, 2003.

The authors would like to thank the Environmental Sciences Strategic Research Fund of Fisheries and Oceans Canada, Ena Macpherson from the Canadian Institute of Fisheries Technology (CIFT) at Dalhousie University and Audrey Mountain from the Biology Department at Dalhousie University for their help in the laboratory work. Special thanks and appreciation from the first author to NSERC and Killiam Trustees of Dalhousie University for their scholarships and generous funding.

Address correspondence to M. R. Islam, Dalhousie University, Faculty of Engineering, D510, 1360 Barrington St., Halifax, Nova Scotia B3J 2X4, Canada. E-mail: rislam@ dal.ca 
Biodiesel (methyl esters of vegetable oil fatty acids) is handled in relatively small quantities and a worst-case scenario spill would be from road tanker haulage. More frequently, spills that occur from handling during refueling are often flushed down the nearest sewer grating, irrespective of any hydrocarbon admixture. This brief study is intended to follow the degradation of the vegetable oil fatty acid methyl esters in such circumstances where bacterial action would probably be important (Dunn and Knothe, 2001). A novel shoreline cleanup process has also been developed to aid in the removal of crude or fuel oil from shorelines using a highly effective biosolvent formulation based on vegetable oil methyl esters in combination with bioremediation enhancers. Mudge and Pereira (1999) conducted experiments using biodiesel derived from vegetable oils to study its effects on the biodegradation of crude oil. They found that the biodiesel demonstrated a considerable potential for removing crude oil from contaminated beaches. Data on the environmental persistence of non-petroleum oils is now required for risk assessments and decision making by spill responders.

The term oil describes a broad range of hydrocarbon-based substances. Hydrocarbons are chemical compounds composed of the elements hydrogen and carbon. The basic unit of fats and oils consists of one molecule of glycerol combined with three molecules of fatty acid, known as a triglyceride. If the material is liquid at ambient temperatures it is traditionally referred to as oil; if solid, as a fat. When all fatty acids of a triglyceride are of the same kind it is a simple triglyceride; if more than one kind is present, it is mixed. The kinds of fatty acid present in a triglyceride have marked effects upon its physical and chemical behavior. When the carbon atoms in the hydrocarbon chain of a fatty acid hold their full complement of hydrogen they are described as saturated. Where two adjoining carbon atoms in the hydrocarbon chain of a fatty acid each lack a hydrogen atom, a double bond forms between them. The fatty acid is then said to be unsaturated (Patterson, 1989).

Environmental Protection Agencies in Canada, USA and many other countries have found that petroleum oils, vegetable oils, and animal fats produce similar environmental effects following accidental spills in the environment as they share common physical properties. Impacts have been shown to result from a number of means including smothering, coating animals and plants with oil, oxygen depletion from the degradation of the oil, and toxicity of the oil and its byproducts. Studies on the environmental persistence of non-petroleum hydrocarbons are now required to determine the level of risk these compounds pose to our environment in the event of accidental spills.

In-situ biodegradation is the elimination of an organic compound from an ecosystem by the metabolic activity of the biocenosis actually present in this system. In theory, if the process was $100 \%$ efficient, the final products of biodegradation are biomass, carbon dioxide, and water. Biodegradability and toxicity can be considered as two basic criteria in determining the behavior of chemical compounds in the environment. Biodegradation can be primary, environmentally acceptable and ultimate (Pitter and Chudoba, 1990). The intensity of biodegradation is influenced by several factors, such as nutrients, oxygen, $\mathrm{pH}$, composition, concentration and bioavailability of the contaminants, chemical and physical characteristics and the pollution history of the contaminated environment. Bioremediation attempts to accelerate the naturally occurring biodegradation of contaminants through the optimization of limiting conditions (Allard and Neilson, 1997).

Many hydrocarbon-contaminated environments are characterized by low or elevated temperatures, acidic or alkaline $\mathrm{pH}$, high salt concentrations, or high pressure. Nevertheless, hydrocarbon-degrading microorganisms have adapted to grow and thrive in these environments and play an important role in recovery of polluted extreme habitats (Margesin 
and Schinner, 2001). Seawater contains a range of microorganisms that can partially or completely degrade oil to water-soluble compounds and eventually to carbon dioxide and water (Dean-Raymond and Bartha, 1975; Tango and Islam, 2002).

In comparison to non-petroleum oils, numerous works has been done to study the environmental factors influencing the biodegradation of petroleum hydrocarbons in marine waters (Atlas and Bartha, 1972; Atlas and Bartha, 1973; Siron et al., 1995; Sharma and Pant, 2000; Tango and Islam, 2002). The processes of spreading, evaporation, dispersion, emulsification and dissolution are most important during the early stages of a spill whilst oxidation, sedimentation and biodegradation are more important later on and determine the ultimate fate of the oil (Blumer et al., 1973).

Vegetable oil spills in fresh water are among the most common organic materials spilled in the United States. As a result, research is being carried out to characterize toxicity and the potential for degradation under both aerobic and anaerobic conditions, with a view of developing new oil spill countermeasure techniques (Sturm, 1973; Wincelle, 2001). In the marine environment, Pereira et al. (1998) studied the bacterial degradation of linseed and sunflower oils in sediments of a salt marsh in North Wales, UK. Biodegradation of the oils was determined by measuring changes in fatty acids composition via GC-MS. Three days after the addition of linseed oil, the numbers of aerobic heterotrophic bacteria increased five-fold to around $1.7 \times 10^{5} \mathrm{cfu} / \mathrm{g}$ wet sediment. This was followed by increases in anaerobic heterotrophs and sulfate reducing bacteria at 7 and 21 days, respectively. Changes in the linseed oil fatty acid composition were noted after 14 days, indicating a degree of degradation had occurred. Pereira et al. (1998) noticed that the addition of sunflower oil to sediments did not affect the numbers of heterotrophic bacteria for over a month. This suggests that the sunflower oil polymerises in sediments makes it resistant to microbial breakdown. Therefore, the degradation of sunflower oil was reduced compared to that of linseed oil.

Canola oil spills are a major concern in Canada. Spills of this product, which now account for more value to the country than wheat, have occurred at a transshipment facility in Vancouver Harbor. Vegetable oil that escaped while being transferred through a pumping station to a tanker at Neptune Bulk Terminals reached Vancouver's Stanley Park and contaminated birds in the harbor (ENS, 2000). Canola and other vegetable oil spills have resulted in massive losses in marine birds (McKelvey et al., 1980; Anon, 1994). The impact and persistent of the product on pelagic and benthic marine organisms are not known.

\section{Experimental Set-up}

One of the main objectives of this study is to investigate and understand the potential biodegradability of representative vegetable and fish oils in the marine environment. This information is needed for risk assessments and decision making in regards to the type and extent of spill response operations needed to protect environmental quality and human health. To accomplish this, the biodegradability of olive, mustard and canola vegetable oils and cod liver oil was studied in controlled laboratory shaker flask experiments. Two ml of each oil was added to $200 \mathrm{ml}$ (1\% volume/volume oil) of seawater and wastewater environments with and without the addition of nutrients. Seawater was taken from the Biology Department Laboratories of Dalhousie University, where it was being pumped into the labs from the North West Arm of the Atlantic Ocean in Halifax after passing through a sand filter. The wastewater was taken a few meters away from the effluent stream near the Halifax harbor. 


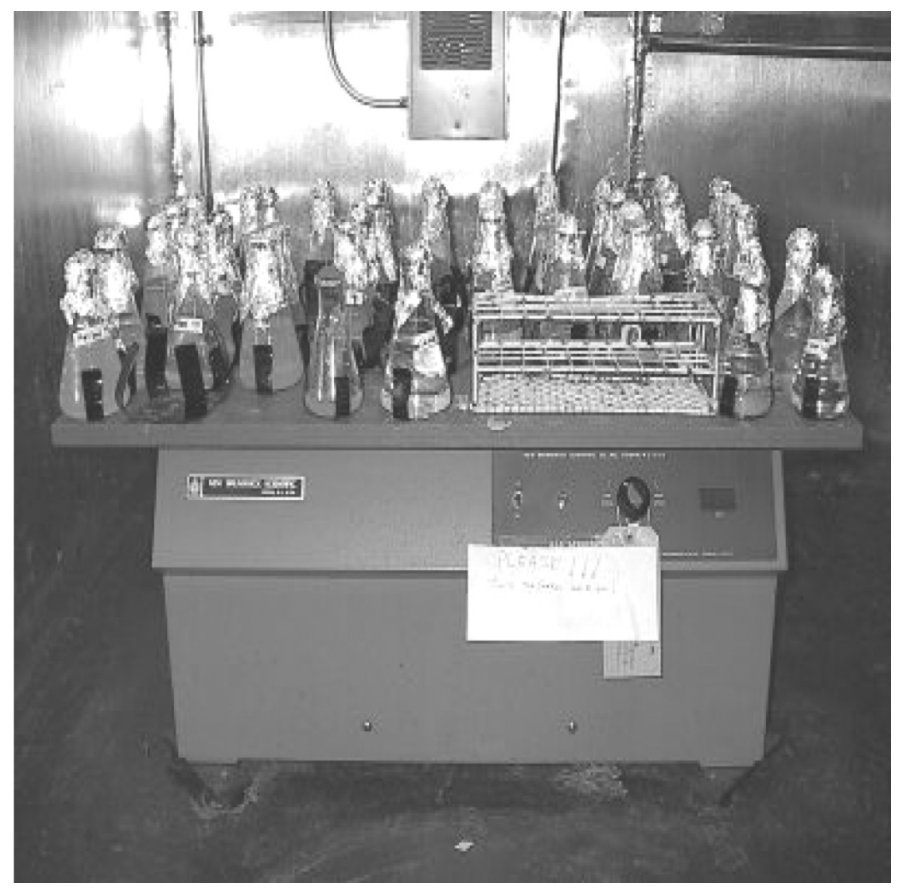

Figure 1. Oil-contaminated samples kept on a shaker in an incubation room at $27^{\circ} \mathrm{C}$.

Marine broth was prepared using seawater and was used as the nutrients enriched seawater samples. The ingredients of the marine broth were peptone $-5 \mathrm{~g}$, yeast extract$1 \mathrm{~g}$, ferriccitrate $-0.1 \mathrm{~g}$, sodium chloride $-19.45 \mathrm{~g}$, magnesium chloride $-5.9 \mathrm{~g}$, sodium sulfate $-3.24 \mathrm{~g}$, calcium chloride $-1.8 \mathrm{~g}$, potassium chloride $-0.55 \mathrm{~g}$, sodium bicarbonate $-0.16 \mathrm{~g}$, potassium bromide $-0.08 \mathrm{~g}$, strontium chloride $-34.0 \mathrm{mg}$, boric acid$22.0 \mathrm{mg}$, sodium silicate $-4.0 \mathrm{mg}$, sodium floride $-2.4 \mathrm{mg}$, ammonium nitrate $-1.6 \mathrm{mg}$, and disodium phosphate- $8.0 \mathrm{mg}$ per liter, with a final $\mathrm{pH}$ of 7.6. The ingredients for the marine agar were the same with the addition of $15 \mathrm{~g}$ of agar. The marine agar and broth used for the bacteria counting was autoclaved for 20 minutes at $121^{\circ} \mathrm{C}$ and 15 psi.

The oil-contaminated samples were put in Erlenmeyer flasks on a shaker $(\mathrm{rpm}=170)$ in an incubator at $27^{\circ} \mathrm{C}$, as shown in Figure 1. Another set of different oil-contaminated samples was kept under static conditions to study the contact area and shaking effects on the biodegradation process. All the samples were studied in duplicates.

Regular surveys of the total number of bacteria in the oil-contaminated samples were performed during the studied period using the plate count method on marine agar petri dishes. The bacteria were grown in an incubator at $27^{\circ} \mathrm{C}$ for 36 hours. The effects of oil type as well as the nutrients and microbial environment (microorganisms present) on the extent and rate of oil degradation were studied. To accomplish this, visual observations, spectrophotometric measurements, bacteria counting, and light microscopic analysis were used.

\section{Results and Discussion}

The oil-contaminated samples in the flasks were visually observed at different time intervals to monitor the microbial growth and the changes in oil droplets shape, behavior, 


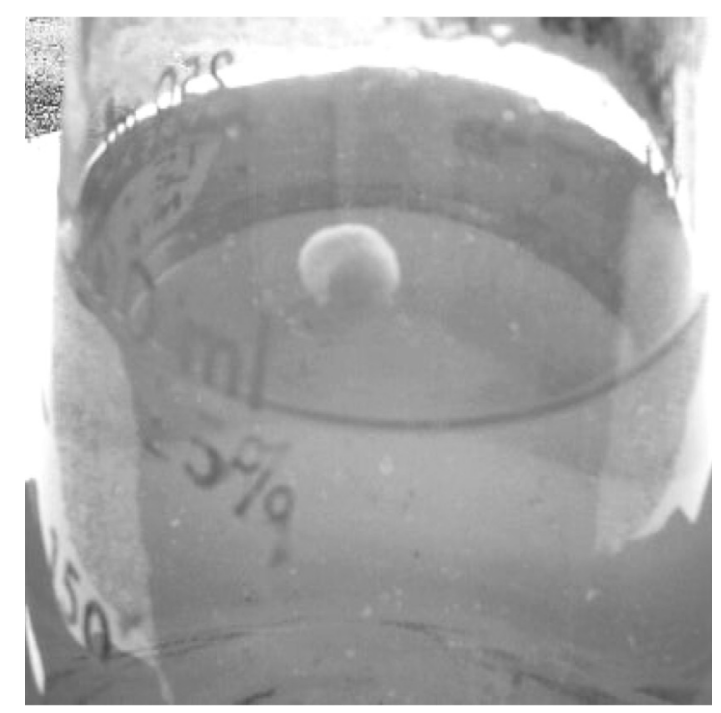

(a)

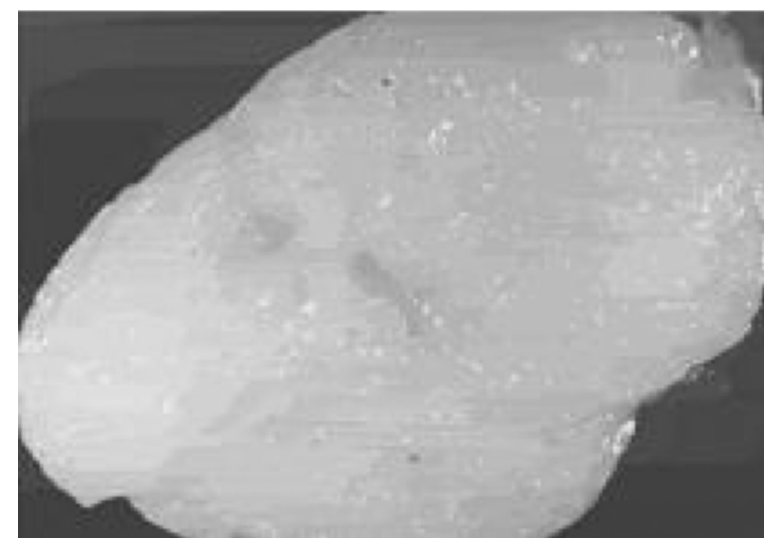

(b)

Figure 2. (a) Canola oil-contaminated seawater sample, $2 \times$; (b) Light microscope picture of one of the floating particles in the sample, $15 \times$.

size, and presence in the sample. Figure $2 a$ shows a canola oil-contaminated seawater sample in which a white spherical particle can be seen floating on the surface and no oil droplets can be seen in the flask. For the canola oil-contaminated wastewater samples, many small white flakes (2-5 mm long) were observed on the surface, while in the seawater containing nutrients samples, the oil droplets disappeared from the surfaces of those samples and no lumps were formed. The white flakes in the wastewater samples were formed much faster than in the seawater only samples.

Following the release of approximately 1500 tons of sunflower oil into the marine environments, Mudge et al. (1995) found that the oil formed a polymer in seawater, and produced relatively hard, intractable lumps. Figure $2 b$ shows a light microscope picture of one of the white particles formed in canola oil samples. The particles dissolved in 


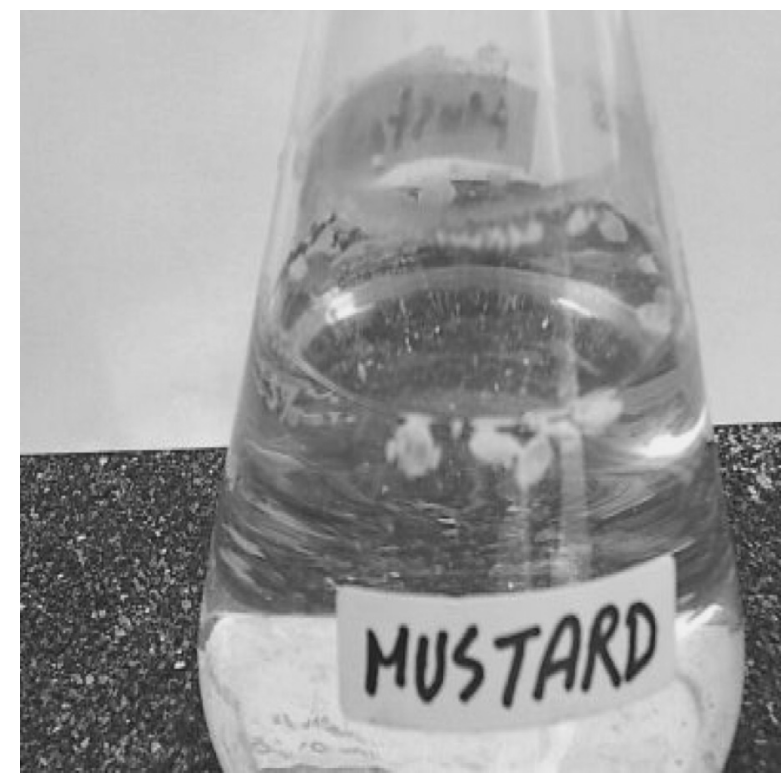

(a)

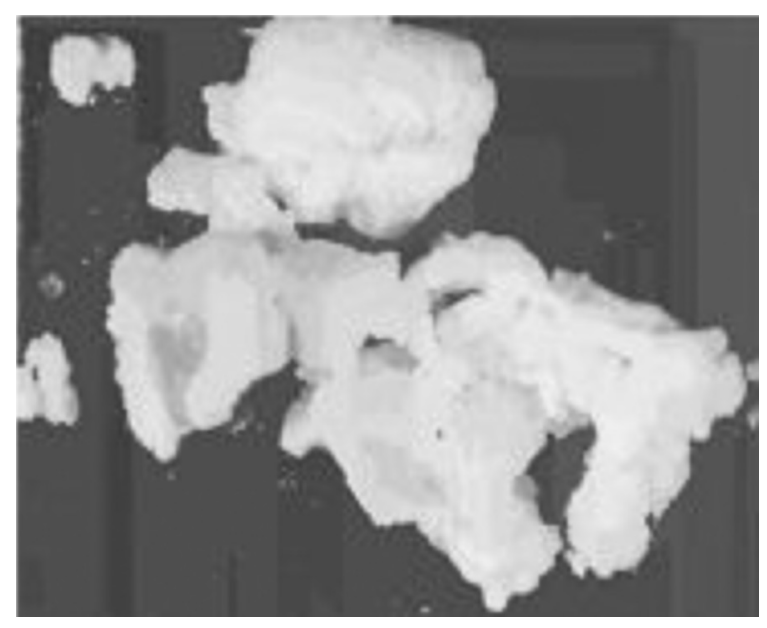

(b)

Figure 3. (a) Mustard oil-contaminated seawater sample, $2 \times$; (b) Light microscope picture of one of the floating particles in mustard oil seawater contaminated sample, $15 \times$.

benzene and chloroform thus providing an indication that they are soaps formed by a saponification process in which triglycerides react with calcium, sodium or potassium hydroxide to produce glycerol and a fatty acid salt (soap).

For the mustard oil-contaminated samples, similar observations were noticed with the exception that many white flakes and lumps were formed and dispersed on the surface and bottom of the flasks. Figure $3 a$ shows the floating particles formed in one of the mustard oil-contaminated seawater samples. Those flakes were observed growing faster 


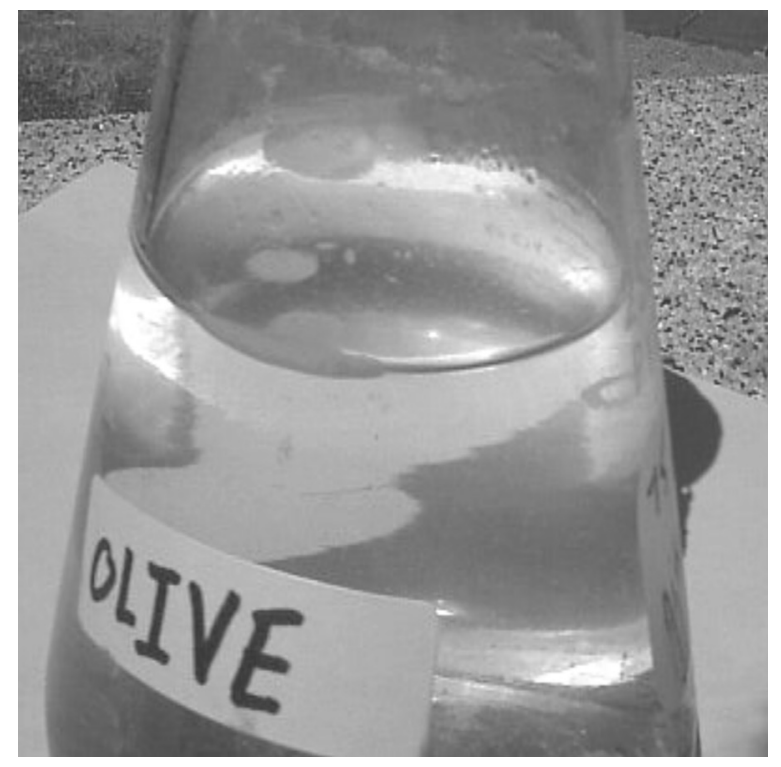

Figure 4. Olive oil-contaminated wastewater sample, $2 \times$.

in the wastewater samples, while in the seawater containing nutrients those flakes were not formed. Mudge et al. (1993) reported that the oil lumps formed after an oil spill were not available for bacterial degradation. Figure $3 b$ shows a picture of one of those fine particles that were formed in the seawater contaminated with mustard oil. Solubility in benzene with heat $\left(100^{\circ} \mathrm{C}\right)$ confirmed that these particles were fatty acid salts (soaps).

Olive oil-contaminated samples were observed to have some oil spots and droplets still floating on the water surfaces even after 30 days. In the seawater samples, big oil droplets (2-4 $\mathrm{mm}$ in diameter) and white spots were observed on the surface. In the seawater containing nutrients samples, the size and concentration of the oil droplets were much smaller compared to seawater only samples (less than $1 \mathrm{~mm}$ in diameter). In the wastewater samples the oil droplets were very fine and few flakes and white spots were formed and dispersed on the surface, as can be seen in Figure 4. No precipitates or floating particles were observed as in the case of canola and mustard oils. Pereira et al. (1998) mentioned that the fates of various types of oils in the same environment are different depending on their viscosity and composition.

In the case of cod liver oil-contaminated samples, it was observed that in the seawater samples there were yellow viscous spots attached to the flask surfaces near the water surface as waxy materials, and few precipitated particles (2-4 $\mathrm{mm}$ in diameter). In the seawater containing nutrients samples, much smaller yellowish particles $(1 \mathrm{~mm}$ in diameter) and spots were observed either precipitated or floating on the water surface. In the wastewater samples, yellowish spherical particles were observed precipitated on the flask bottoms, as can be seen in Figure $5 a$. Figure $5 b$ shows a magnified picture using a light microscope for one of those cod oil lumps. These particles were easily dissolved in chloroform. Thus as reported for canola oil, they are fatty acid salts and not polymerized oil. Many researchers (Parker, 1967; Kemp et al., 1975; Perry et al., 1979) reported that polyunsaturated fatty acids have preferential degradation relative to saturated acids under the same environmental conditions. 


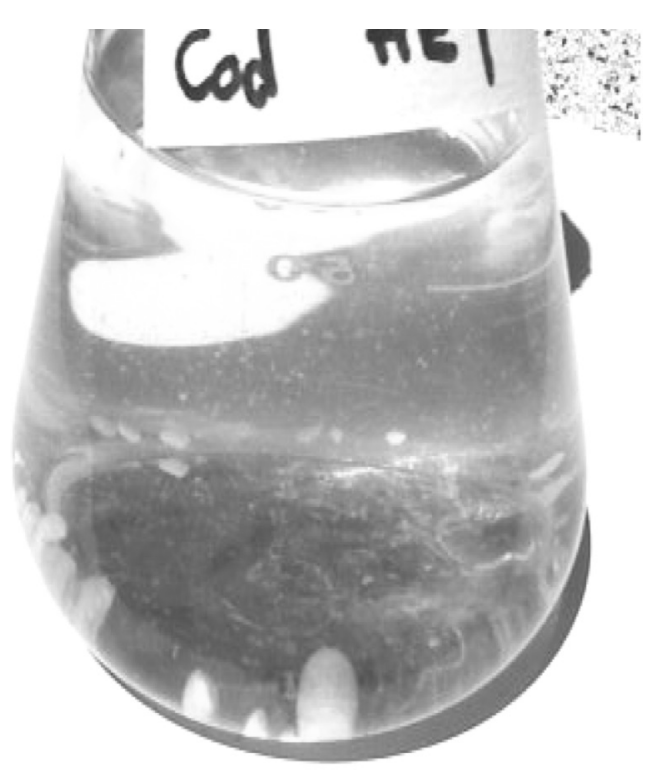

(a)

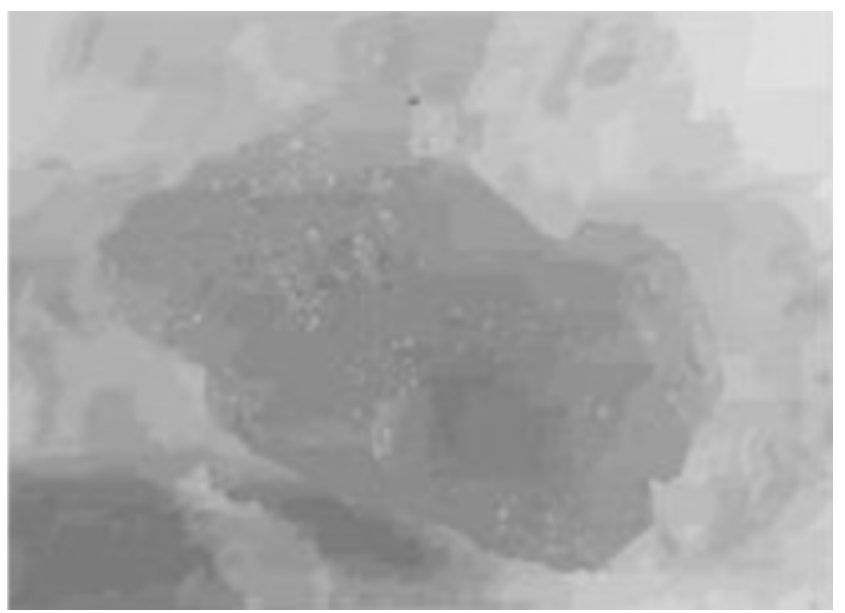

(b)

Figure 5. (a) Cod liver oil-contaminated wastewater sample, $2 \times$; (b) Light microscope picture of one of the precipitate particles in the mustard oil-contaminated wastewater sample, $15 \times$.

To study the contact area effects on the biodegradation process, a few oil-contaminated samples were kept under static conditions. These samples were compared with the corresponding samples that have been kept on the shaker during the study period. The visual observations as well as bacteria numbers monitoring showed an increase in oil degradation and bacteria numbers with shaking. In a wastewater sample contaminated with high canola oil concentration (a layer that covers the whole water surface), a polymeric thin white to gray film was observed at the interface between the oil and water phases. 
This film increased in thickness and size with time until it became heavy, collapsed and precipitated on the flask bottom (Figure 6). This film is believed to be a mix of fatty acid salts and oil polymeric materials.

The total bacteria populations for the different samples and at different time intervals were monitored using the plate count method using marine agar petri dishes. The spectrophotometer was used at the beginning of the experiments to monitor the bacterial growth in the canola oil-contaminated samples. Even the first readings indicated a clear and measurable bacterial growth in the canola oil-contaminated samples compared to the control samples (seawater alone), plate counts were used for bacterial enumeration. Due to the oil viscosity, and the presence of dispersed fine oil droplets on the surface and sometimes suspended in the solution as white particles, all of those reasons affected the accuracy and the repeatability of the spectrophotometer results.

In general, it was observed that the numbers of marine oil degrading bacteria increased with time in the oil-contaminated samples. The increase in bacteria populations was more pronounced in both the seawater containing nutrients and wastewater samples. Figure 7 shows the increase in bacteria numbers for the three different canola oilcontaminated samples (seawater, wastewater, and seawater containing nutrient). Mudge et al. (1995) studied the biodegradation of sunflower and linseed oils and reported an increase in bacteria numbers due to the presence of oils.

Figures 8-11 show the bacteria populations in the different oil-contaminated samples during the period of study. It's obvious that both availability of nutrients and mixed microbial environments enhance the degradation process. By comparing the bacterial numbers for each oil with the corresponding numbers of other oils under the same conditions and time interval, and by taking advantage of the visual and microscopic observations, it can be concluded that canola oil degraded with the least difficulty followed by mustard, cod and finally olive oils. Figures 8-11 show an irregular trend in the data depending on the oil type and environment. Those findings can be explained by understanding the effect of oil structure and composition on the degradation processes.

The structure of a fatty acid molecule that is characterized by the length of the carbon chain (number of carbon atoms), the number of double bonds and also the exact position of these double bonds, define and determine the biological reactivity of the fatty acid molecule and even of the lipid containing those fatty acids. Olive oil is the richest in monoenes fatty acids. They have a unique double bond and the commonest are of the $n-9$ series, as oleic acid, which is probably the most common fatty acid (olive oil has a high content of this acid: about $60-70 \%$ ). This is why it is the most stable compared to other types of oils studied, and that means it is expected to be the hardest to degrade. Linoleic acid is the most common polyunsaturated fatty acid in plants and animal tissues. Canola oil contains around 33\% linoleic acid, which is polyunsaturated fatty acid. Olive oil contains less than $10 \%$ of this fatty acid and this is why canola oil is more susceptible to degradation than olive oil. On the other hand, mustard oil contains up to $50 \%$ monounsaturated erucic acid with 22 carbon atoms. This is why it is much easier to degrade compared to olive oil.

Table 1 shows that the percentages of fatty acids in mustard seed oil are $7 \%$ saturated, $63 \%$ monounsaturated and 30\% polyunsaturated fatty acids. Oils from fish and marine origins are characterized by a large range of fatty acids from 12 to 26 carbon atoms and 0 to 6 double bonds. The bulk of the fatty chains are contributed by saturated (15-25\%), monoenes (35-60\%) and polyenes (25-40\%). Gadoleic acid with 20 carbon atoms was first noted in cod liver oil. Among all the oils studied in this investigation, cod liver oil is considered the least stable oil and as a result the easiest to be degraded (Ratledge, 1994). 


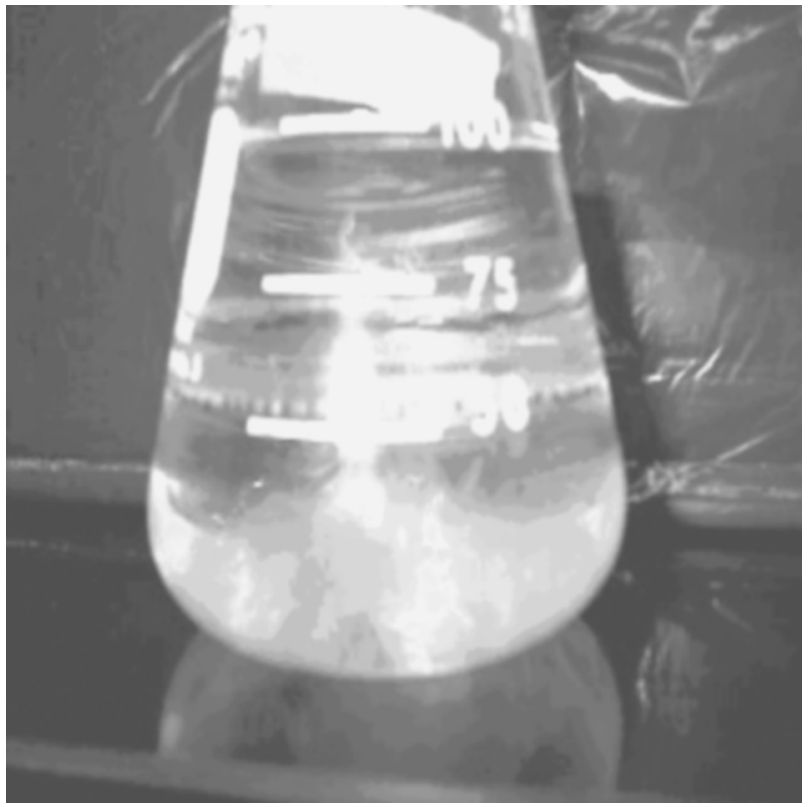

Figure 6. Polymer film formation at the interface of oil and water phases in a canola oil-contaminated wastewater sample, $2 \times$.

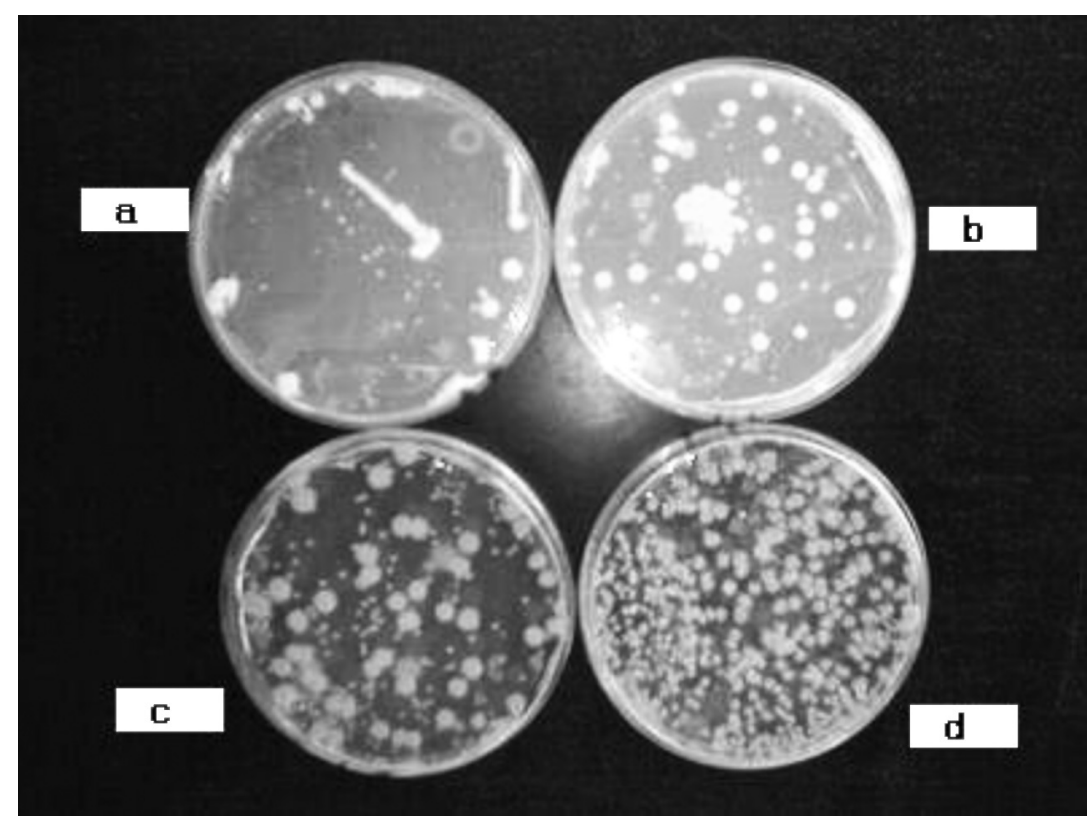

Figure 7. Bacteria colonies in (a) seawater control sample, and the different canola oil-contaminated samples; (b) seawater; (c) seawater containing nutrient; (d) wastewater, after 2 days of growth in the shaker flasks. 


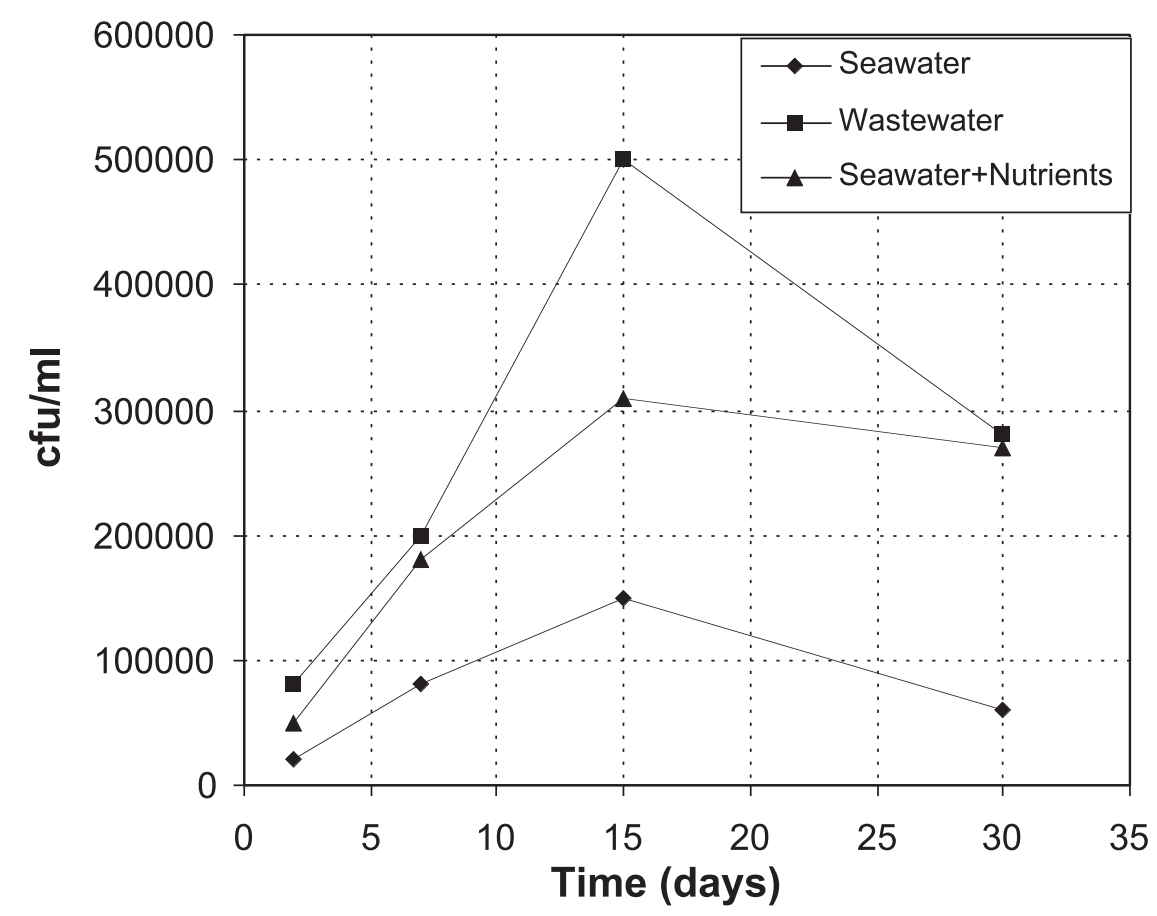

Figure 8. Bacteria numbers in the canola oil-contaminated samples.

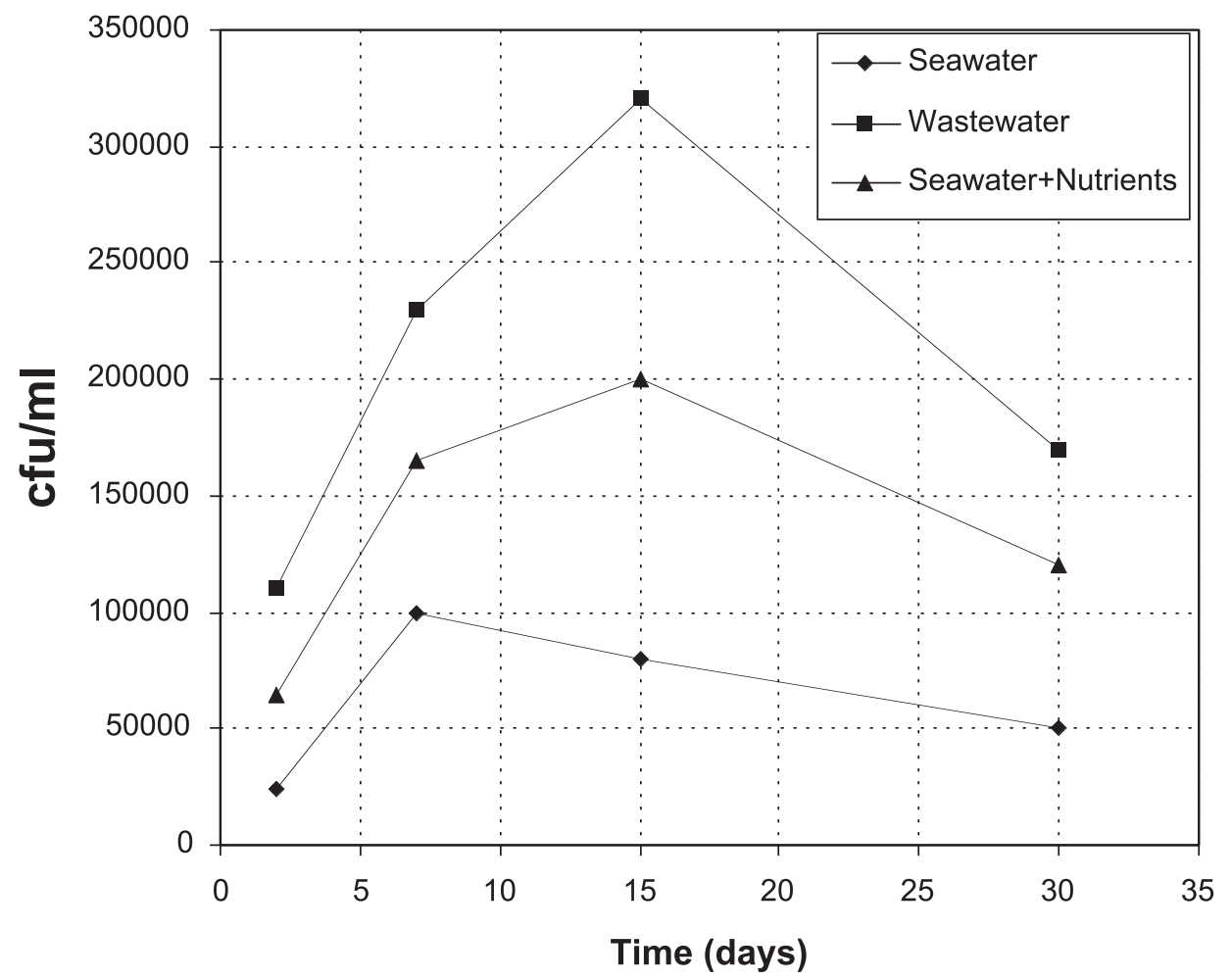

Figure 9. Bacteria numbers in the mustard oil-contaminated samples. 


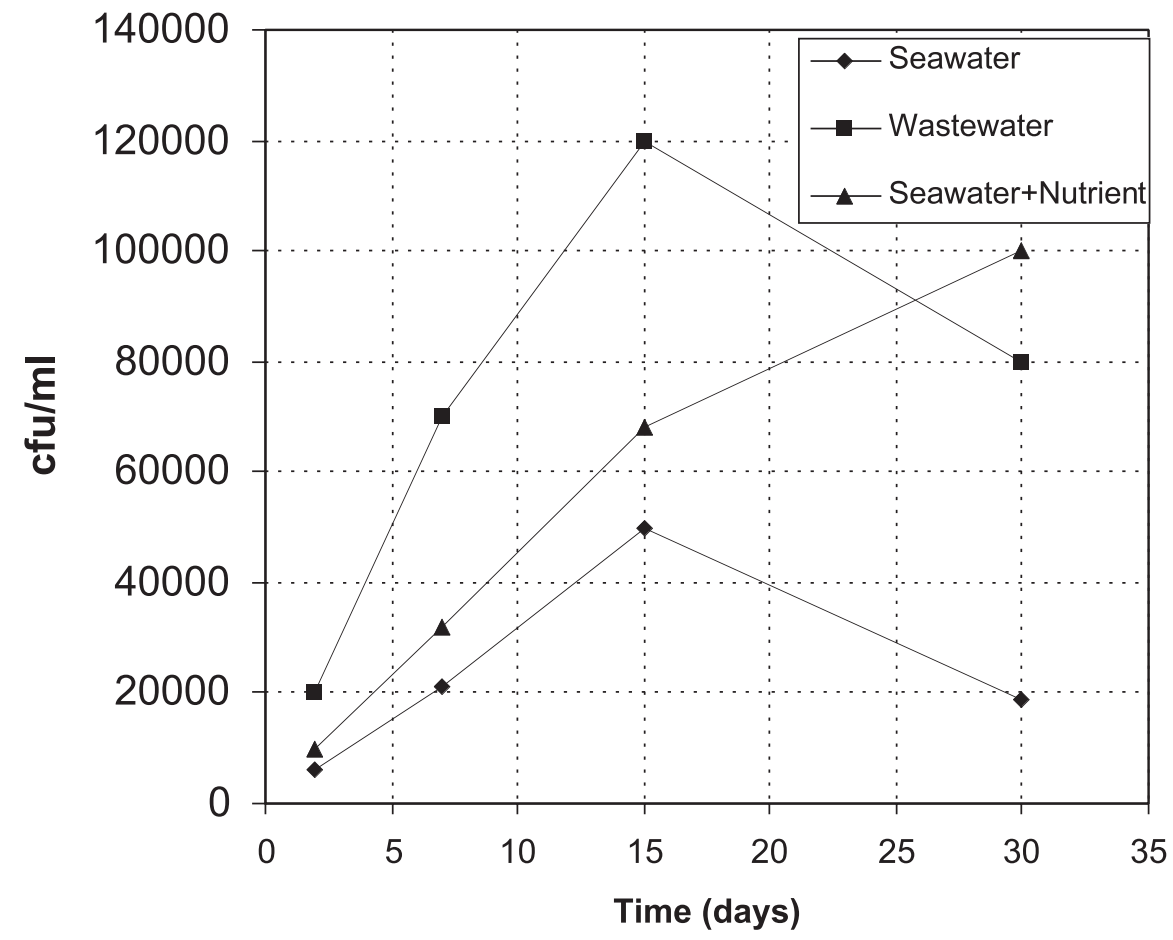

Figure 10. Bacteria numbers in the olive oil-contaminated samples.

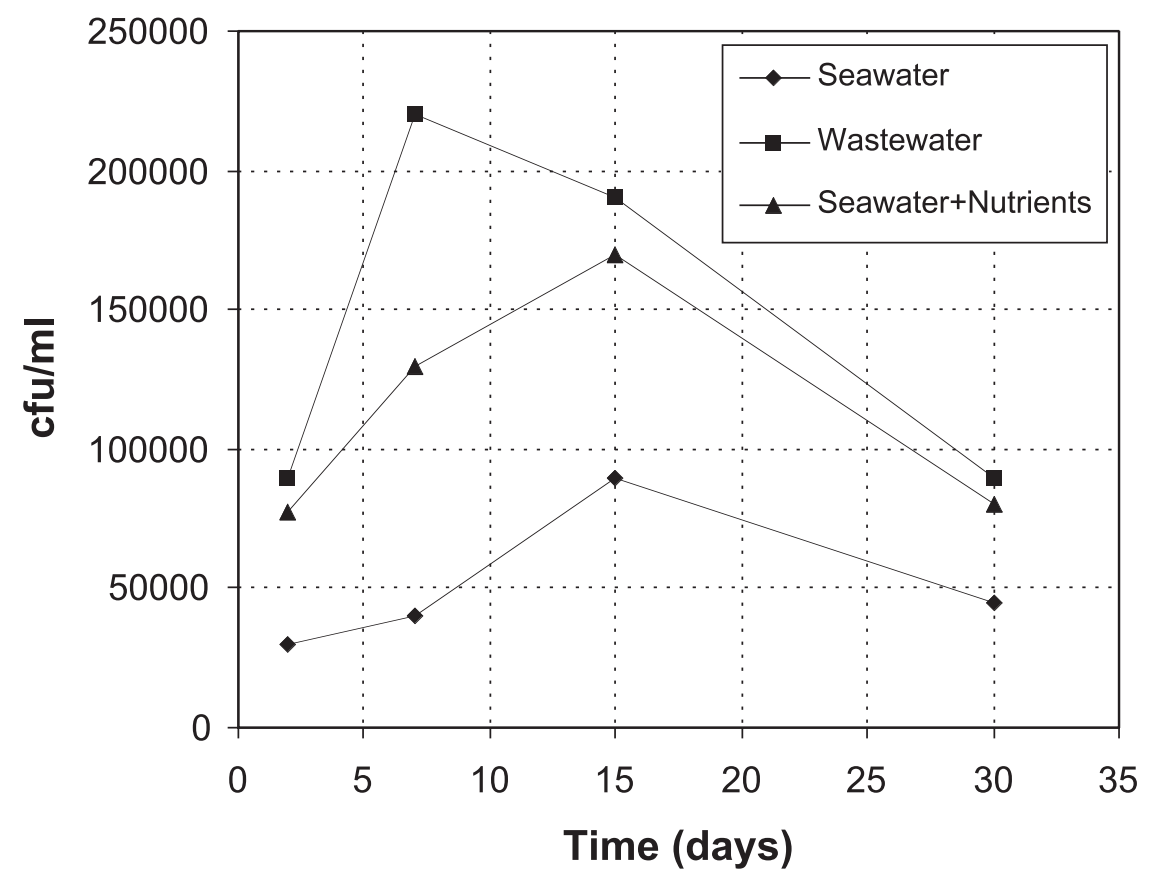

Figure 11. Bacteria numbers in the cod liver oil-contaminated samples. 
Table 1

Saturated and unsaturated fatty acids percentages of representative natural oils

\begin{tabular}{lcccc}
\hline & \multicolumn{4}{c}{ Oil } \\
\cline { 2 - 5 } \multicolumn{1}{c}{ Fatty acid } & Olive & Canola & Mustard & Cod \\
\hline Total saturated & 15 & 6 & 7 & 21 \\
Total monounsaturated & 75 & 60 & 63 & 52 \\
Total polyunsaturated & 10 & 34 & 30 & 27 \\
\hline
\end{tabular}

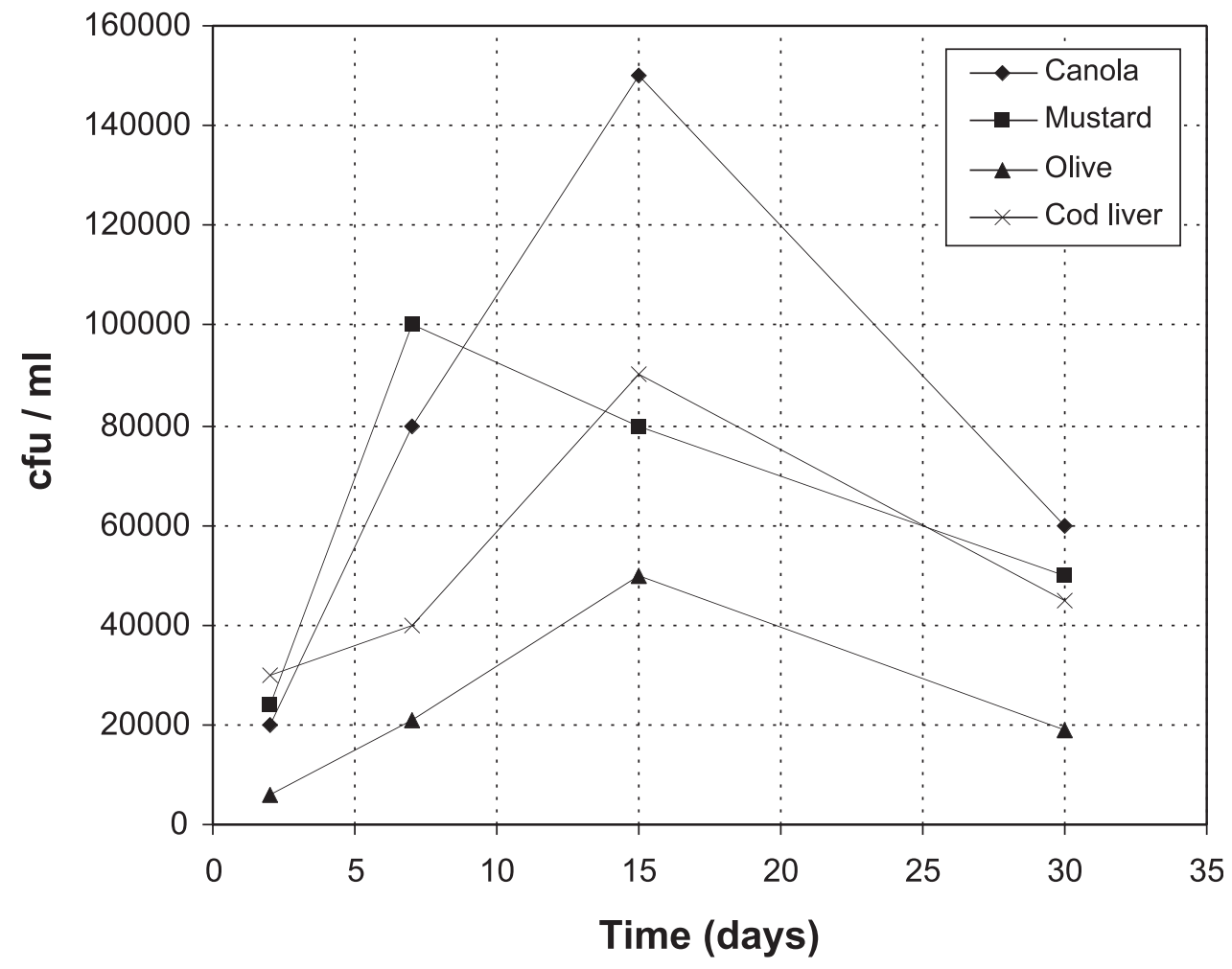

Figure 12. Bacteria numbers in the seawater oil-contaminated samples.

That was not the case in some samples, and the antibacterial products (Erickson et al., 1980) that come from the oxidation of cod liver oil explain that. The observations, experimental results and bacteria numbers (Figures 12-14) in the different oil-contaminated samples are in agreement with the above discussion concerning oil stability, composition, and availability for biodegradation. As can be seen from Figures 12-14, bacteria numbers were, in general, the highest in the canola oil-contaminated samples, followed by mustard, cod, and olive oil samples.

As well as the biodegradation processes, auto-oxidation is taking part in the oil deterioration with time. Examining the results can prove this observation. This fact may 


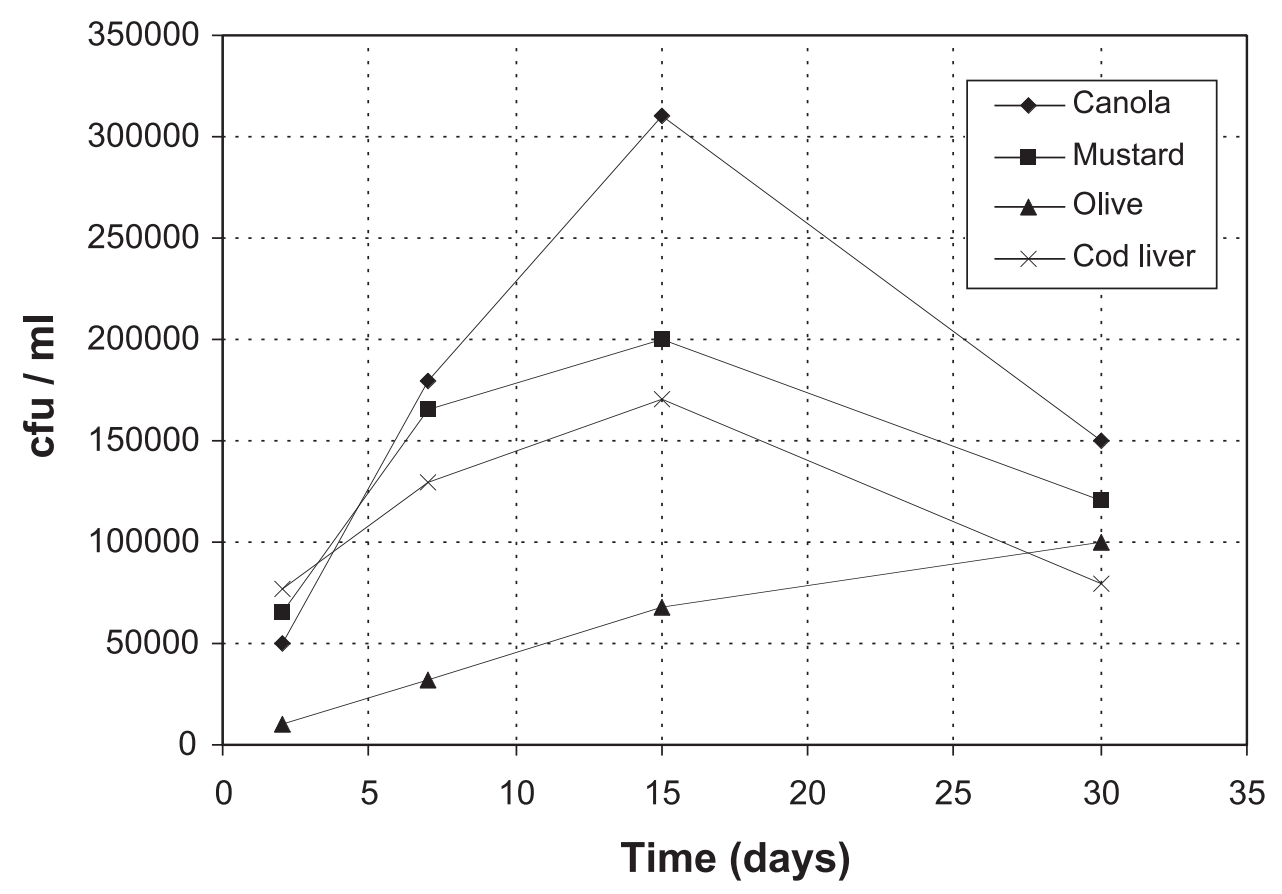

Figure 13. Bacteria numbers in the oil-contaminated seawater enriched with nutrients samples.

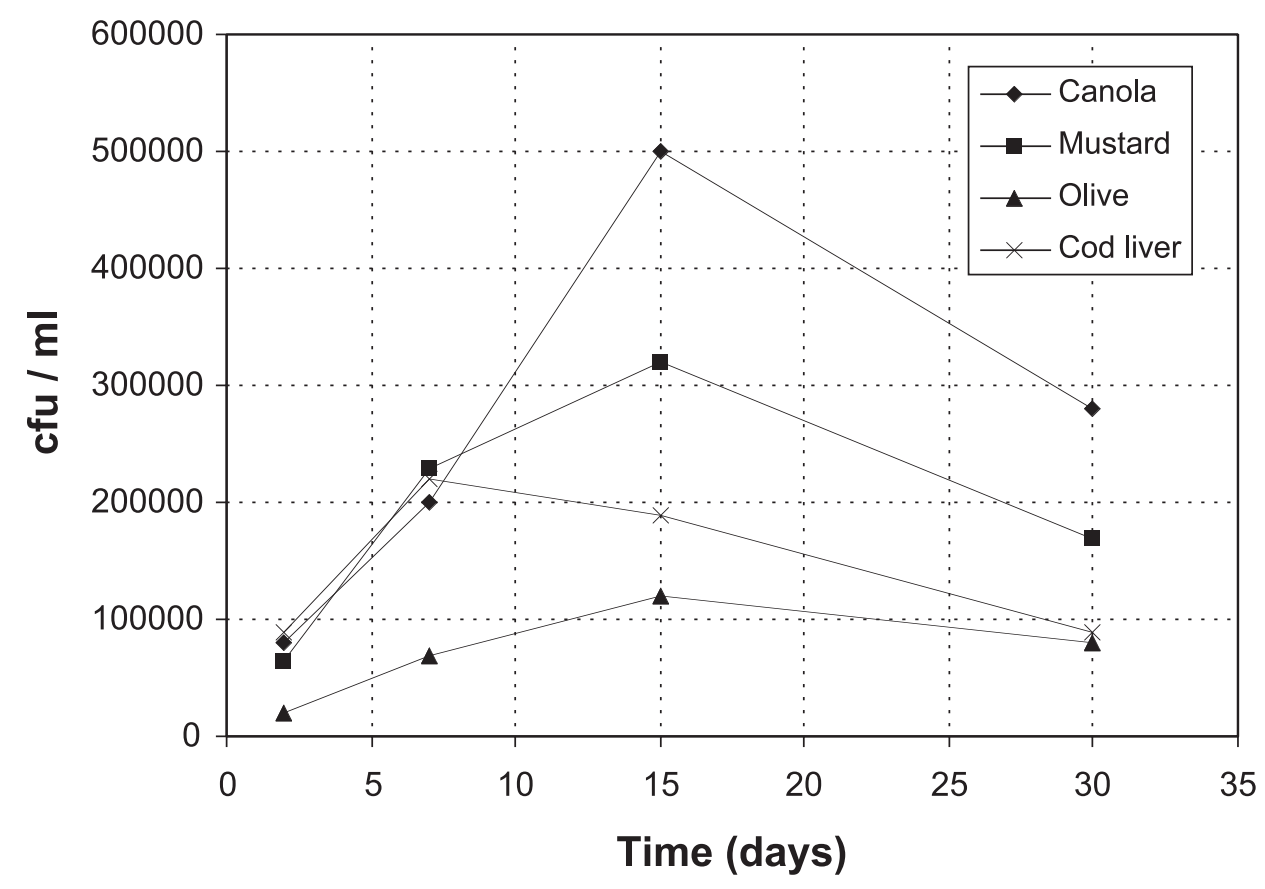

Figure 14. Bacteria numbers in the oil-contaminated wastewater samples. 
be explained also by the decrease in the bacterial colonies with time depending on the oil type, as can be seen in Figures 8-11. The decrease in bacteria numbers may also be explained by running out of bioavailable substrate as the physical characteristics have changed. Nutrients limitation may also be a key role in that observation. Cod liver oil produces the highest antibacterial products followed by mustard, canola, and olive oil. This explains the sharp decrease in bacterial numbers in cod liver and mustard oil samples. The lack of nutrients after a long time is another cause of the sharp reduction in bacteria populations after reaching the peak value (Figures 8-14) (Ratledge, 1994).

Lipid peroxidation can be defined as the oxidative deterioration of lipids containing any number of carbon-carbon double bonds (Ratledge, 1994). The primary peroxidation products are hydroperoxides in which double bond(s) may have moved or/and changed configuration. These products may be structurally rearranged or converted into secondary peroxidation products, either smaller molecules by fission or bigger by dimerization. Some of the products of auto-oxidation have antibacterial properties that may kill the bacteria or cause bacterial stat. The toxicity of the byproducts of oil metabolism processes is known as well, and has been studied by many researchers (Ratledge, 1994).

\section{Conclusions}

All results clearly revealed a significant response of the oil-contaminated samples to both the seawater and wastewater environments. The oil biodegradation processes in seawater were found to be significantly stimulated by nutrient enrichment and by the presence of mixed microbial consortia found in wastewater. It was also observed that different oils responded in different rates and extents to biodegradation depending on their viscosity, structure and compositions.

Visual observations showed that canola oil degraded with the greatest ease, followed by mustard, cod, and finally olive oil, which was the most stable oil used in this study. Bacteria numbers in the different samples showed a different trend for the different types of oils. Taking the effect of both the degradation susceptibility of each oil, and the antibacterial activity of metabolic byproducts for oil degradation, canola oil had the highest degradation, followed by mustard, cod and finally olive oil.

Both auto-oxidation and biodegradation took place in the oil weathering process. The oxidation process either accelerates the biodegradation rates by producing much smaller and easier compounds to be biodegraded, or inhibits the microbial attacks by producing antibacterial products.

The formation of floating lumps may provide an operational advantage to spill responders, as the recovery of residual oil particles may be removed much easier than surface oil slicks. This concludes that bacteria populations of marine environments have the potential to degrade different types of oils in different rates and pathways.

\section{References}

Allard, A. S., and A. H. Neilson. 1997. Bioremediation of organic waste sites: A critical review of microbiological aspects. Int. Biodeterior. Biodegrad. 39:253-285.

Anon. 1994. Danger from edible oil spills debated again. Lipid Technology 6:40-44.

Atlas, R. M., and R. Bartha. 1972. Biodegradation of petroleum in seawater at low temperatures. Can. J. Microbiol. 18:1851-1855.

Atlas, R. M., and R. Bartha. 1973. Abundance, distribution and oil biodegradation potential of microorganisms in Raritan Bay. Environ. Pollut. 4:291-300. 
Blumer, M., M. Ehrhardt, and J. H. Jones. 1973. The environmental fate of stranded crude oil. Deep Sea Res. 20:239-259.

Dean-Raymond, D., and R. Bartha. 1975. Biodegradation of some polynuclear aromatic petroleum components by marine bacteria. Developments in Industrial Microbiology 16:97-110.

Dunn, R. O., and G. Knothe. 2001. Alternative diesel fuels from vegetable oils and animal fats. J. Oleo Sci. 50:415-426.

ENS, The Environment News Service (ENS). (Feb. 2000). Canola Spill in Vancouver Harbor Oils Birds. http://ens.lycos.com/ens/feb2000/2000L-02-14-03.html. Accessed Aug. 25, 2002.

Erickson, D. R., E. H. Pryde, O. L. Brekke, T. L. Mounts, and R. A. Falb. 1980. Handbook of Soy Oil Processing and Unilization. St. Louis, MO: American Soybean Association and Champaign, IL, American Oil Chemists' Society.

Kemp, P., R. W. White, and D. J. Lander. 1975. The hydrogenation of unsaturated fatty acids by five bacteria isolates from the sheep rumen, including new species. J. Gen. Microbiol. 90:100-114.

Margesin, R., and F. Schinner. 2001. Biodegradation and bioremediation of hydrocarbons in extreme environments. Appl. Microbial Biotechnol. 56:650-663.

McKelvey, R. W., I. Robertson, and P. E. Whitehead. 1980. Effect of non-petroleum oil spills on wintering birds near Vancouver. Mar. Pull. Bull. 11:169-171.

Mudge, S. M., and G. Pereira. 1999. Stimulating the biodegradation of crude oil with biodiesel preliminary results. Spill Science and Technology Bulletin 5(5/6):353-355.

Mudge, S. M., I. D. Goodchild, and M. Wheeler. 1995. Vegetable oil spills on oil marshes. Chemistry and Ecology 10:127-135.

Mudge, S. M., M. A. Salgado, and J. East. 1993. Preliminary investigations into sunflower oil contamination following the wreck of the M. V. Kimya. Mar. Poll. Bull. 26:40-44.

Parker, P. L. 1967. Fatty acids in recent sediment. Marine Science 12:135-142.

Patterson, H. B. W. 1989. Handling and Storage of Oilseeds, Fats and Meal. London: Elsevier Science.

Pereira, M. G., S. M. Mudge, and J. Latchford. 1998. Bacterial degradation of vegetable oils in marine sediments. Chemistry and Ecology 14:291-303.

Perry, G. J., J. K. Volkman, R. B. Johns, and H. J. Bavor. 1979. Fatty acids of bacterial origin in contemporary marine sediments. Geochim. Cosmochim. Acta 43:1715-1725.

Pitter, P., and J. Chudoba. 1990. Biodegradability of Organic Substances in the Aquatic Environment. Boca Raton, Fla.: CRC Press.

Ratledge, C. 1994. Biochemistry of Microbial Degradation. London: Kluwer Academic Publishers.

Sharma, S. L., and A. Pant. 2000. Biodegradation and conversion of alkanes and crude oil by a marine Rhodococcus sp. Biodegradation 11:289-294.

Siron, R., E. Pelletier, and C. Brochu. 1995. Environmental factors influencing the biodegradation of petroleum hydrocarbons in cold waters. Arch. Environ. Contam. Toxicol. 28:406-416.

Sturm, R. N. 1973. Biodegradability of nonionic surfactants: Screening test for predicting rate and ultimate biodegradation. J. Am. Oil Chemists Soc. 50:159-167.

Tango, M. S., and M. R. Islam. 2002. Potential of extremophiles for biotechnological and petroleum applications. Energy Sources 24:543-559.

Wincelle, D. 2001. Clay-Oil Interactions for the Anaerobic Bioremediation of Vegetable Oil Spills. MSc Thesis. Environmental Engineering. Washington University. St. Louis, USA. 